\title{
CULPABILIZACIÓN DE LAS VÍCTIMAS Y RECONOCIMIENTO: LÍMITES DEL DISCURSO MEDIÁTICO SOBRE LA VIOLENCIA DE GÉNERO
}

\author{
VICTIM BLAMING AND RECOGNITION: BOUNDARIES \\ OF MEDIA DISCOURSE ON GENDER VIOLENCE
}

\author{
Emma GÓMEZ NiCOLAU \\ Universitat de València
}

Recibido: 11/01/2016

Aceptado: 10/05/2016

\section{Resumen}

Dada la relevancia que se le ha otorgado a los medios de comunicación para combatir la violencia de género, el presente artículo trata de discutir las limitaciones que imprime el actual marco hegemónico de reconocimiento de la violencia de género para la actualización de un discurso mediático que profundice en la realidad del fenómeno y contribuya al cambio social. Se ha optado por una metodología cualitativa para poner en el centro de la investigación a los y las periodistas que elaboran, enmarcan y seleccionan las noticias de violencia de género. Se hicieron 17 entrevistas semiestructuradas y, a través del análisis del discurso, se analiza el proceso de interpelación a los sujetos de la violencia y a la sociedad en su conjunto que se activa desde los contextos de producción de las noticias. En el texto se argumenta cómo el actual modo de reconocimiento de la violencia de género propicia una concepción individualizada de la violencia que produce un modelo de mujer-víctima objetualizada, carente de agencia y alterizada a la que, en definitiva, se responsabiliza de la situación que experimenta.

Palabras clave: violencia de género, medios de comunicación, reconocimiento, análisis del discurso, periodistas.

\footnotetext{
Abstract

Media have been given an outstanding relevance to combat gender violence. The aim of this article is to discuss the limitations of the current hegemonic mode of recognition
} 
of gender-based violence if we want to update media discourse in order to deepen in the reality of the phenomenon and contribute to social change. A qualitative approach has been developed to put in the center of the research those journalists that make, frame and select gender-based violence news stories. 17 semi-structured interviews were made and, through discourse analysis, we analyze how journalists interpellate the subjects of violence in the context of news production. It is argued that the current mode of recognition of gender violence fosters an individualized conception of violence that produces an objectified model of woman-victim considered lacked of agency, who, eventually, is judged responsible of her own situation of violence.

Keywords: gender-based violence, media, recognition, discourse analysis, journalists. 


\section{INTRODUCCIÓN ${ }^{1}$}

El interés académico por los modos de representación de la violencia de género en los medios de comunicación ha consolidado una línea de investigación propia en el Estado español que se suma a las investigaciones internacionales que, desde los 70, pondrán de relevancia el poder de los medios a la hora de construir el género (De Lauretis 1987). Estos esfuerzos se han traducido en una innegable mejora del tratamiento informativo cuyo gran logro ha sido la consolidación de la violencia de género como un problema social relevante (Berganza; Carballido; Vives). El desarrollo de un nuevo marco de interpretación sobre la violencia de género (De Miguel) reforzará lo que se ha denominado como «discurso hegemónico sobre la violencia de género» (Casado; García Selgas, Casado; Rodríguez Martínez).

A pesar de las mejoras y la incorporación de un enfoque temático sobre la violencia de género en los medios, las investigaciones -y la crítica feminista- siguen denunciando la presencia de elementos recurrentes más allá del contexto español: la centralidad del hecho violento y la recreación del crimen como gancho para captar audiencias (Fairbairn, Dawson 148; Gómez Nicolau); la culpabilización de las víctimas de las agresiones vividas por sus malas decisiones, su baja calidad moral o por optar por estilos de vida alejados de la norma (Gilchrist; Jiwani, Young; Meyers); la justificación de las agresiones a través de la asociación entre la masculinidad y la violencia (Cuklanz); o la búsqueda de porqués de las agresiones para individualizar la violencia (Fagoaga).

Recientemente se ha incidido en cómo la construcción de la identidad mediática del sujeto de la violencia de género (Gámez Fuentes 2012, 2013; Gámez Fuentes, Núñez Puente; Núñez Puente, Fernández Romero) no responde a la heterogeneidad de las condiciones sociales en las que se experimenta la violencia sino que lo hace a una «hipervisibilidad identitaria de ciertas construcciones mediáticas que finalmente han delimitado la inteligibilidad de

1. Este artículo se enmarca en el proyecto La re-significación de la mujer-víctima en la cultura popular (FEM2015-65834-C2-2-P), Programa Estatal de Fomento de la Investigación Científica y Técnica de Excelencia, Ministerio de Economía y Competitividad. 
la identidad del sujeto víctima desde una posición hegemónica que presenta como reconocible en el discurso al sujeto objetualizado» (Núñez Puente, Fernández Romero 274). El sujeto objetualizado tendrá, como principal característica asociada, la carencia de agencia. En este sentido, Cuklanz destaca cómo «los personajes femeninos que son víctimas han sido tradicionalmente representados dotados de escasa agencia para ayudarse a sí mismos, con pocas redes de apoyo de amistades y familia, a menudo se encuentran asistidas por hombres más fuertes y competentes, y son frecuentemente culpabilizadas, al menos en parte, de su victimización» (Cuklanz 33). Años atrás Eulalia Lledó advertía que "es altamente remarcable que a lo largo de todas las informaciones y noticias sobre agresiones contra mujeres jamás se ha hallado la más mínima mención a alguna aptitud, habilidad o pericia física en el momento de esquivar o huir de una agresión referida a una mujer concreta» (Lledó, citada en Bengoechea 9). La falta de agencia se verá reforzada por el predominio de fuentes oficiales como la policía y las instituciones judiciales que se encargarán de definir, evaluar y determinar la violencia de género y que se erigen en filtros de la representación (Gámez Fuentes 2012).

Las reflexiones teóricas y los análisis sobre el actual modo de representación de la violencia nos llevan a plantearnos por qué los medios tratan la violencia como la tratan. Para indagar en esta cuestión, hemos puesto a los y las periodistas que habitualmente elaboran, enmarcan y seleccionan las noticias sobre violencia de género en el centro de la investigación. A través de un planteamiento metodológico cualitativo, indagamos los esquemas de percepción, apreciación y acción de los y las periodistas sobre violencia de género y sobre la práctica profesional del periodismo como herramienta para contribuir al cambio social.

La tesis que se sostiene en este artículo es que la culpabilización de las víctimas y la negación de la agencia de las mujeres constituyen los elementos centrales y complementarios a través de los que se tejen las tramas discursivas sobre violencia de género en los medios de comunicación. Tramas que, a su vez, se incardinan en el discurso hegemónico gestado en la arena políticomediática -basado en la gubernamentalidad a distancia de la violencia: las políticas asistenciales, punitivas y del orden moral- que se construye desde la noción de sujeto moderno. Un principio que limita considerablemente el reconocimiento de los sujetos de la violencia, (re)produciendo así la construcción de lo masculino y lo femenino a partir de una relación dicotómica sujeto-objeto. 


\section{OBJETIVOS Y METODOLOGÍA. TELEVISIÓN, PERIODISTAS Y ANÁLISIS DEL DISCURSO}

Poner a los y las profesionales de la información en el centro de la investigación viene motivado tanto por la posición que ocupan como «los principales dispositivos de producción y reproducción del capital simbólico» (Callejo 9), como por su papel como mediadores entre la realidad de la violencia de género y la percepción social de la violencia de género. En los análisis sobre los modos de representación mediática de la violencia de género, muchas veces se desatiende que, efectivamente, los productos están creados por alguien en un contexto de producción determinado. Son, de hecho, los contextos de producción los que a menudo propician la reproducción de los modos de visibilización de la violencia de género y la estaticidad en las fórmulas de representación: rutinas periodísticas, la organización jerárquica de las redacciones, los criterios de noticiabilidad o la proximidad del campo periodístico al campo del poder político y científico. Y, en este contexto, los y las periodistas ponen en circulación, de manera colectiva, percepciones, posicionamientos y juicios de valor que ordenan los límites de lo pensable.

Este trabajo se concibe como un ejercicio de exploración del proceso de codificación de los discursos periodísticos sobre violencia de género. Siguiendo la tesis establecida por Stuart Hall, el proceso de codificación estará determinado por los significados e ideas que comprenden desde el conocimiento operativo de las rutinas de producción y las habilidades técnicas a las ideologías profesionales, el conocimiento institucional, pero también las definiciones, ideas y prejuicios sobre las audiencias a las que dirigen sus mensajes (Hall 219). En este sentido, entendemos que, además de condensar las tensiones y conflictos propios del campo periodístico, la codificación de los mensajes incorpora tanto la dimensión ideológica, política y ética respecto a los géneros y las violencias, pero también y sobre todo, la imagen hegemónica de la violencia de género y de las personas que son identificadas como víctimas y agresores en los marcos de reconocimiento establecidos. El objetivo, por tanto, es acceder al universo simbólico de los y las periodistas con respecto al papel que le otorgan a los medios de comunicación en la lucha contra la violencia de género y analizar los marcos de reconocimiento que articulan respecto a los sujetos de la violencia: víctimas y agresores.

Para ello, se realizaron 17 entrevistas semiestructuradas, entre abril de 2010 y enero de 2013, a periodistas de las cadenas de televisión generalistas públicas y privadas del Estado español que habitualmente elaboran, enmarcan y seleccionan las noticias sobre violencia de género. Para tratar de dar cuenta de las tensiones propias del campo periodístico, se seleccionaron a 
profesionales que ocupasen posiciones diversas en el campo dependiendo del puesto de trabajo ocupado -y, por tanto, capacidad de decisión (edición, jefatura de sección, coordinación o redacción)-, pero también según el grado de especialización en la temática (especialista en la temática, periodista encargada habitualmente del tema pero sin formación ni consideración como experta, ocasional y nunca) y en medios con trayectorias diversas en el tipo de cobertura periodística que ofrecen sobre violencia de género y en la incorporación de material deontológico al respecto. En este sentido, TVE, como cadena estatal pública, le había otorgado una importancia destacada a la violencia de género (con una cobertura preeminentemente temática) y disponía de códigos específicos desde principios de los 2000. TV3 y Canal 9 (regionales públicas) mantenían una posición muy diferente: TV3 contaba desde 2002 con un protocolo que se actualizó en 2009 y se caracteriza por ofrecer un enfoque temático, sin cobertura de sucesos. Además, contaba con un organismo regulador del audiovisual, el CAC, que realiza estudios de seguimiento del tratamiento informativo de la violencia de género en los medios audiovisuales catalanes. Canal 9, la televisión generalista valenciana, clausurada el 27 de noviembre de 2013, se caracterizaba por un uso intensivo de los sucesos y por realizar una cobertura de la violencia preeminentemente episódica. No contaba con herramientas de autorregulación propias ni códigos explícitos, desarrollaba una cobertura similar a la de las cadenas privadas, Telecinco y Antena 3. Cuatro, ya parte de Mediaset en el momento de realizar las entrevistas, mantenía un perfil más bajo en cuanto a la información de tipo episódica y La Sexta estaba en proceso de revisión y actualización de sus protocolos de cobertura sobre el tema ${ }^{2}$.

La muestra, por tanto se ha construido propiciando la variabilidad de posiciones de partida a partir de cuatro dimensiones principales: el sexo, el medio en el que trabajan, el grado de especialización y la capacidad de decisión en cuanto a los contenidos que se incluyen y su enfoque. Los textos que constituyen el corpus de análisis -las transcripciones literales de las entrevistas- «están producidos por diversos 'discursos' concretos que se entretejen en el magma de la interacción verbal» (Conde 36). Con su análisis trataremos de fundamentar algunas de las características del discurso mediático sobre la violencia de género en la medida que, de acuerdo con Fernando Conde, presenta una coherencia narrativa, está dotado de cierta forma narrativa particular, se expresa en una serie de argumentos verbales, emerge de las condiciones

2. Un análisis pormenorizado de los contextos de producción, la trayectoria de las cadenas en la cobertura de la violencia de género y la introducción de material deontológico se encuentra en Gómez Nicolau. 
concretas de la entrevista como instrumento para la producción de discursos sociales y se pronuncia con cierta intencionalidad (37-39). Así pues, el objetivo es analizar el universo de significaciones que se comparten en el campo periodístico y que promueven una determinada representación mediática de la violencia de género atendiendo: al papel de los medios para definir la violencia de género como un problema social y la interpelación que persiguen los mensajes hacia binomio víctima-agresor.

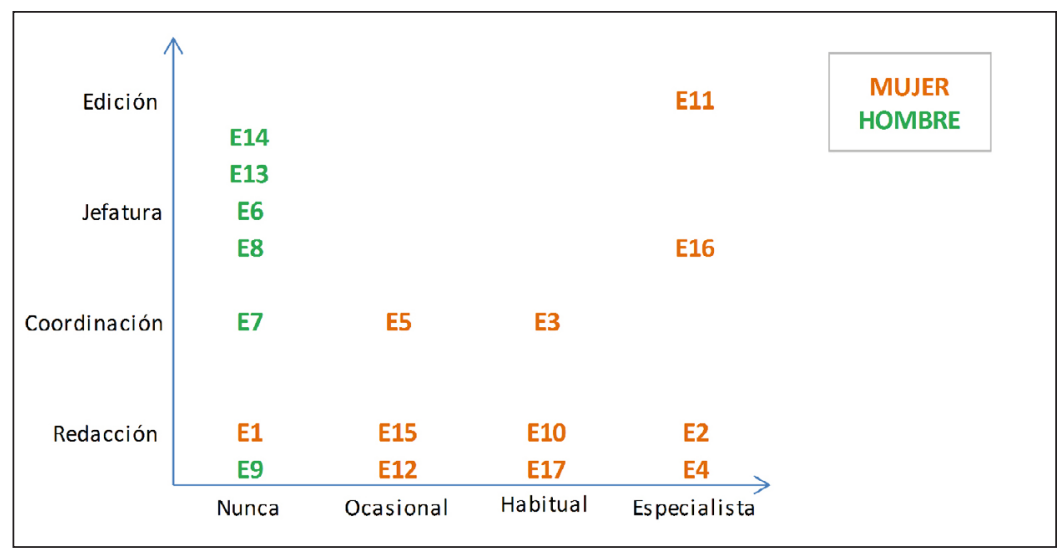

Figura 1. Distribución de las personas entrevistadas según grado de especialización, capacidad de decisión y sexo.

Las entrevistas semiestructuradas se realizaron en Madrid, Barcelona y Valencia, en dependencias de las redacciones o en cafeterías cercanas a sus puestos de trabajo. Las entrevistas duraron de 45 a 90 minutos y, en ellas se trataron temas relativos a la organización del trabajo, los hábitos y rutinas en la cobertura de la violencia de género y los esquemas de percepción, apreciación y acción sobre la violencia de género y la práctica profesional.

\section{CONTEXTOS DE ACCIÓN: MEDIOS PARA GOBERNAR LA VIOLENCIA}

Merece la pena recordar que la violencia machista hacía referencia en los años 80 a la violencia sexual. El significado, así pues, se ha ido transformando a la luz de las reivindicaciones del movimiento feminista y delimitando bajo la acción del Estado. Cabe, así pues, delimitar el concepto de violencia que estamos utilizando. El proceso de introducción de la violencia de género como problema social en el Estado español ha estado marcado por su reducción conceptual a la violencia de pareja heterosexual cuando esta se ejerce sobre las mujeres (García Selgas, Casado), eliminando la complejidad que imprime 
su análisis desde la dimensión del espacio público y desde el nivel estructural y centrando el debate en la dimensión individual tanto de quienes agreden como de quienes son agredidas. En el contexto de institucionalización del feminismo, la lucha contra la violencia primero doméstica y de género después, constituirá un punto de convergencia de planteamientos feministas diversos (Rodríguez Magda; Verdugo). No obstante, tras la emergencia de la lucha por la reforma del Código Penal -como instrumento penalista- y la introducción del marco de análisis «de género», se produjo la retirada del movimiento feminista del espacio político (Maqueda; Marugán, Vega 2002) y quedaba en manos de las instituciones públicas primero y de los medios de comunicación después (Marugán, Vega 2001, 7).

La violencia de género, entendida ya como problema político en España, se concibe políticamente como un fenómeno que puede ser gobernado, minimizado e incluso erradicado desde la acción de las políticas públicas en tres ejes principales: el de la asistencia a las víctimas, el de la persecución de los agresores y el de la instauración de una nueva legitimidad democrática racional que sustituyese la legitimidad tradicional del maltrato (Miranda 38). Atendiendo este último eje, los medios de comunicación se situarán en el centro de las políticas públicas, como herramientas de sensibilización, trasladando a los medios la responsabilidad de la lucha contra la violencia. Esta mirada sobre la violencia se ratificará con la aprobación de la Ley 1/2004 de Medidas de Protección Integral contra la Violencia de Género que considerará los medios como una institución más -junto al sistema penal y los servicios sociales- para gobernar la violencia.

La mirada moral sobre los medios entenderá que si se controla el discurso, se controla la violencia. Más allá de considerar o cuestionar los medios como sistemas de producción del género por su capacidad de delimitar los horizontes interpretativos de los fenómenos sociales, o por posibilitar alterar la agenda política, o por poner en circulación discursos dominantes, esta tendencia postula que las variaciones a la hora de representar la violencia tienen un impacto sobre la misma. Pero, tal y como señala Teresa de Lauretis, hay que diferenciar entre el signo, el significado y el objeto -expresión, contenido y referente- (De Lauretis 1985, 18). En el caso del tratamiento mediático de la violencia, solo entran en juego los dos primeros, no así el tercero, que pertenece al mundo de los cuerpos. Hay, de hecho, una evolución en la dimensión público-política de los planteamientos sobre medios de comunicación y violencia. Los primeros trabajos de investigación encargados por organismos públicos (Fagoaga; Fernández; López Díez; Lledó, por citar solo algunas obras de referencia) pondrán de manifiesto cómo las noticias se producen desde el 
androcentrismo. Después, la eclosión de materiales deontológicos, guías y recomendaciones para una mejor cobertura de la violencia de género que se publicarán a lo largo de los años 2000 (Bolinches; IORTV) fruto de la introducción definitiva de la violencia de género en la agenda pública, reiterarán la necesidad de alterar los parámetros de la cobertura tradicional, minimizando el amarillismo y privilegiando un enfoque de servicio público. Ahora bien, a finales de la primera década de los 2000, por el contrario, se hará evidente la responsabilización de los medios a través de la popularización de la teoría del efecto imitación, entendida como el efecto multiplicador de casos de mujeres muertas tras la aparición de noticias sobre las mismas.

Esta hipótesis fue mantenida por Miguel Lorente, Delegado de Gobierno para la Violencia de Género en los años 2010 y 2011. En el estudio preliminar encargado a la Universidad de Granada se concluía que las muertes por violencia de género no respondían a un patrón temporal aleatorio y se daba una concentración de casos. Se afirma que «si en un instante se comete un femicidio el riesgo de que se cometa un femicidio en el instante inmediatamente posterior es 1,67 veces mayor y ese incremento es significativo. Por tanto, hay un incremento del riesgo de femicidio si en el instante anterior hay un femicidio» (Luna del Castillo 4). Los resultados de este estudio preliminar se utilizaron como un espacio de trabajo con los medios, aunque fuese preventivo, y así se trasladó a las empresas de comunicación ${ }^{3}$.

Los medios, así pues, en el proceso de introducción de la violencia de género en el discurso público, no sólo se convierten en el elemento fundamental para dar a conocer la violencia de género sino que se interpretan como uno de los elementos cruciales para corregirla. Para los y las periodistas, sensibilizar, concienciar o dar visibilidad -que conforman la cadena de significados ligados a la responsabilidad social del periodismo- sitúa el discurso periodístico como centro a partir del cual terceras personas pueden renegociar sus actitudes:

En medios de comunicación falta seguir haciendo reportajes de concienciación, y seguir tratando el tema con delicadeza, y seguir mostrando el rechazo social, o sea, lo que más efecto ha hecho contra los maltratadores, lo que más ha parado los pies y lo que más ha animado a las mujeres a denunciar es el rechazo social. Y el rechazo social se obtiene a través de los medios de comunicación. Porque está mal hecho, porque mostramos lo que no está bien

3. La visita de Lorente como Delegado del Gobierno para la Violencia de Género a las redacciones fue uno de los temas que surgieron en las entrevistas y que se interpretaba, por parte de los y las periodistas, como un punto de inflexión en la cobertura de la violencia de género en sus empresas. 
y lo que antes en un bar la gente aplaudía: yo a esta me la cargo, ahora dice, «oye, ¿qué dices?» (E2)

El periodismo se reivindica como institución capaz de resolver problemas a partir del principio de enunciación, recogiendo los principios de servicio público: proporcionar conocimiento al informar sobre un determinado problema social; modular la aceptabilidad del público; motivar al público para actuar con responsabilidad y propiciar marcos de significación respecto a las decisiones que se toman voluntariamente (Farré, Gonzalo 15). Una mirada que, como veremos, tiende a la individualización de los problemas sociales y, en el caso que nos ocupa, a derivar la responsabilidad una vez los medios han conseguido «abrir los ojos en cierto modo» (E5) o «poner los puntos sobre las íes en este sentido» (E10) enfatizando la función interpelativa: su capacidad de dirigirse a las audiencias y a los sujetos de la violencia.

\section{ESTIMULAR LA DENUNCIA, INSTITUCIONALIZAR LAS RESPUESTAS}

Los profesionales subrayan el papel de los medios para dar soluciones a las personas que están inmersas en una situación de violencia. La interpelación, sin embargo, se orienta a las mujeres víctimas hacia las que lanzan un mensaje de «toma de consciencia» seguido de la información útil para que puedan, individualmente, evitar una agresión:

Es un poco una proyección para mucha gente que a lo mejor está en su casa y dice: «Ah, pues a mí me pasa eso». (E5)

Yo por ejemplo, a mí me gusta la sección en la que estoy y el trabajo que hacemos porque creo que es el periodismo que se tiene que hacer que es el de lanzar mensajes, por ejemplo, concienciar a la gente, sensibilizarlos, prevenir, que las mujeres sepan que existen ayudas, que existe policía, que existen sistemas en los que si a ti te falta casa porque te vas a quedar en la calle, que tienes un piso... (E12)

A través del acceso al discurso mediático, pues, las mujeres que experimentan una relación violenta podrían transitar desde una posición de sujetos sujetados a otra en que se erigen como sujetos de la acción. Para los y las periodistas, la función enunciativa ejercida por los medios permite que las mujeres, una vez interpeladas, tomen la palabra y sigan el proceso marcado por las instituciones: llamar al teléfono de atención, denunciar, acudir a un centro de recuperación y rehacer su vida como supervivientes. Para recuperar la categoría de sujeto se pasaría, temporalmente, por un estado de sujeción por parte de las instituciones policiales y judiciales. 
Este punto de partida de la interpelación se sustenta sobre los fundamentos del sujeto moderno: centrado, capaz y situado en el centro de la historia que puede, a través de la toma de conciencia, restituir su posición de sujeto. "Cuéntalo, hay salida a la violencia de género», el último eslogan de la campaña del Ministerio de Sanidad, Servicios Sociales e Igualdad, evoca ese camino seguro al que se accede a través de la toma de la palabra primero, y del uso de las instituciones después.

El marco hegemónico de interpretación de la violencia como aquella que se ejerce contra las mujeres por el hecho de ser mujeres propicia esta interpretación, usando el género como eje igualador de la desigualdad. No obstante, las aproximaciones interseccionales advierten de la necesidad de incorporar los análisis de los múltiples ejes de opresión que constituyen los contextos de la violencia (Sokoloff, Dupont). Los procesos de empobrecimiento, la etnia, la orientación sexual y la identidad agravan las dificultades a las que se enfrentan las personas que sufren violencia desde los márgenes. Sin embargo, estas dificultades no pueden entenderse como particularidades individuales sino como fruto de posiciones sociales que están atravesadas por dimensiones estructurales (Jiwani). El discurso hegemónico que recalca que «la violencia nos afecta a todas» oculta que nos afecta de maneras diferentes.

Y, en la práctica del periodismo, el discurso hegemónico sobre la violencia de género se enfrenta a realidades que se alejan del principio igualador del género. De hecho, relatan imágenes muy diferentes a la idea de mujer que se sobrepone de una situación de violencia a través del uso de las herramientas institucionales. Las periodistas más especializadas, las que salen al campo, se encuentran con: mujeres que denuncian reiteradamente, mujeres que no denuncian, mujeres que no rompen la relación... una casuística que, efectivamente, las aleja de esa posición de sujeto moderno ilustrado capaz de dar cuenta de sí mismo (Butler). Encuentran unos sujetos que no encajan en el principio de sujeto moderno, con los que no se reconocen y a los que, por tanto, dejan de interpelar desde el discurso mediático:

Pero yo sí que creo que podemos, eh, nuestro mensaje va más dirigido a lo que rodea a la mujer, o sea, a la familia de la mujer, que creo que sí que sería fundamental, creo que un 0,1 sólo de las denuncias que se pusieron el año pasado fue, las pusieron familiares de las mujeres, que me parece brutal, o sea, ¿qué están haciendo las familias? (E3)

El desplazamiento de la interpelación hacia el entorno supone una transferencia de responsabilidad, negando totalmente la agencia de los sujetos implicados en relaciones violentas. De esta manera, el tránsito de sujeto sujetado a sujeto agente se rompe con la interposición de un tercer sujeto encargado 
de tomar la agencia perdida de la mujer-víctima que dejará de estar dotada de conocimiento externo, objetivo y capaz de evaluar y sancionar. La pregunta recurrente, ¿por qué se quedan las mujeres?, dibuja los límites al reconocimiento de los sujetos de la violencia que no ofrecen lo que se considera, desde el discurso hegemónico, como la única vía legítima para ser reconocidas: la denuncia.

Para buscar esa promoción de la denuncia, los y las periodistas utilizarán diversas estrategias discursivas. Una de ellas será la visibilización de los menores que conviven con relaciones violentas como víctimas que, para los y las profesionales, se entiende como un instrumento de presión a las mujeres para que busquen salidas:

Y luego sobre todo porque eso animaría también a muchas mujeres, es decir, en definitiva, si tú estás sufriendo malos tratos y alguien te cuenta que tus hijos también lo están sufriendo por su culpa, a lo mejor es más fácil que tú des el paso y luches contra eso. (E1)

Esta estrategia responsabilizará a las mujeres de la seguridad y salud de sus hijos e hijas, haciendo uso de la figura materna de cuidado y dedicación a los menores -se hace referencia a un mandato materno aunque, en ningún caso, aparecerá un mandato paterno. El proceso de codificación está atravesado por el constructo de la mujer víctima de malos tratos presa de la falsa consciencia, inconsciente de su propia situación.

...pues que lo hizo delante de los hijos. «Es que -decía Lorente- es que eso es, al final, es irrelevante». No, yo no creo que sea irrelevante. Yo creo que te da un perfil de un agresor que permite a muchas víctimas que no saben en qué medida deben denunciar a su marido, el que digan: «iQue éste no ha respetado ni a sus hijos! Y yo que pienso que mi marido me pega lo justo y no lo hace más porque están mis hijos delante, pues empiezo a pensar que cualquier día se le cruza el cable y ni con niños delante. O que además de matarme a mí, maltrata a los niños, pues dices tú, es que también a mis hijos lo hace». Entonces, eso ayuda a tomar conciencia a las víctimas, pero también a la sociedad y a las familias a ayudar a denunciar. A decir, «Oye, Fulana Mari que tu marido cualquier día hace lo mismo contigo o mira el caso de ayer, es que te veía ayer a ti. O sea era ella, pero te veía a ti y veía a tus hijos». (E6)

El discurso mediático objetualiza así los sujetos de la violencia de género, considerándolos inconscientes de lo que se percibe como inequívocas señales de violencia: situaciones objetivas de violencia que existen independientemente de la experiencia concreta. Así, el sujeto reificado de la violencia es heterodesignado por parte, ya no sólo de las instituciones cuyo etiquetaje tiene efectos performativos, sino también por parte del discurso mediático. 
Dado que la denuncia se interpreta como la estrategia legítima para salir de la violencia, de la responsabilización se transita a la culpabilización cuando se retira la denuncia articulando un doble juego argumental: En primer lugar, niega toda capacidad de agencia de las mujeres más allá de la denuncia. Paterson advierte que «las mujeres resisten de maneras muy diversas incluyendo la obediencia y la sumisión, el engaño, la ruptura formal o informal de la relación, la intervención de las instituciones, la reducción a la exposición, la intervención de la policía, la salida del hogar y la venganza violenta, incluyendo el homicidio» (Paterson 2), también utilizan sus redes sociales y comunitarias y construyen respuestas autónomas y singulares de acuerdo a la posición social que ocupen. En segundo lugar, obvia las consecuencias que tiene para las personas situadas en situaciones de dominación, utilizar instrumentos como el poder judicial. Conviene recordar cómo, desde la criminología feminista (Howe; Larrauri; Maqueda, Paterson) se ha destacado que los procesos judiciales resultan hostiles para las mujeres que denuncian a sus compañeros. Las autoras han advertido de: la desconfianza hacia las declaraciones de las mujeres, la falta de recursos económicos que se ponen a su disposición, o la falta de consideración hacia la persona que pone la denuncia por lo que respecta a la información que se le suministra sobre el procedimiento y los plazos. La vía penal, de acuerdo con las autoras, es una estrategia, no la solución, y a menudo se vuelve en contra de las que denuncian: porque no cubre sus expectativas, porque absuelve a la otra persona, porque no dota de recursos... De acuerdo con Larrauri: «el sistema penal puede favorecer la creación de estereotipos que las perjudican. Por ejemplo, se repite el mito de lo irracionales que son las mujeres que pretenden desistir del proceso penal, en aras de una reconciliación o en un intento de minimizar la violencia; se alude a las mujeres que denuncian penalmente o para conseguir ventajas en la separación; o, contrariamente, se señala el absurdo proceder de las mujeres que denuncian y luego no quieren separarse» (Larrauri 275). En el discurso de los y las periodistas, cobran vida estas percepciones que Larrauri identifica con el discurso de la judicatura:

Sabes, porque lo que más me llamó la atención de cuando hice el reportaje de 24 horas en el juzgado es ver cómo una chica que su madre y su hermana denunciaron por ella porque un día llegó a casa destrozada de golpes, con cortes, porque su marido, su pareja, la había echado contra el baño y se había cortado..., esa chica acudió a declarar ante el juez, ante la jueza en ese caso, de la mano del chaval que le había pegado. O sea, ¿qué hay detrás de la cabeza de esa mujer, o...? En ese caso, el entorno de esa chica no le había fallado, pero en la mayoría de los casos el entorno falla porque nadie, nadie da la cara por ellas. Nadie denuncia. (E10) 
La diversidad de posiciones y experiencias que encierran las decisiones de las mujeres quedan borradas en el proceso de construcción mediática de la mujer víctima de violencia de género. Independientemente de la posición estructural que ocupen, la misma catalogación como víctimas les arrebata su capacidad de agencia, siempre que esta no pase por los canales institucionales reglados. La estrategia del silencio a la que se refiere Osborne para hacer callar a las voces disidentes con el discurso hegemónico, se materializa en la negación de todo testimonio que no concuerde con lo que se identifica como el camino de salida de la violencia que se interpretará como un obstáculo para luchar. Siguiendo a Moorti, los testimonios se seleccionarán siempre que no contradigan el discurso oficial. Las otras, las que se identificarán como erráticas o irracionales, no tienen voz en las pantallas; como mucho, sólo forman parte de la escena filmada:

Pues yo qué sé, yo, por ejemplo, cuando he intentado hacer, claro, hubo un momento, que hace ya mucho tiempo, que ahora ya se habla más, pero al principio no se hablaba de que las mujeres estaban retirando las denuncias y volviéndose a ir a vivir con los agresores y tal y no sé qué. Pues [...] me fui a un juzgado y veías a la mujer llorando porque no quería que se llevaran detenido al tipo que le había pegado la noche anterior, ¿sabes? Entonces, yo hago eso, no porque la mujer que me vea en su casa diga «Ah, pues no voy a retirar la denuncia», porque me parece tan compleja (!) la, la, por lo que está pasando esa mujer que, evidentemente, porque yo le diga en la tele que no retire la, la, sino para que la gente que se encarga de esas mujeres lo tenga en cuenta, ¿sabes? (E3)

Así pues, cuando la realidad desborda la categoría mujer-víctima reconocida, los medios dejan de interpelarla. Butler advierte que la capacidad de interpelar tampoco implica obligatoriamente el reconocimiento y, al mismo tiempo, el juicio, por importante que sea, no puede hacer las veces de teoría del reconocimiento. De hecho, continúa, bien podemos juzgar a otro sin reconocerlo en absoluto (Butler 67). En los discursos provenientes del campo periodístico, la interpelación primera se torna juicio que, finalmente, constituye una manera más de culpabilizar a las mujeres que experimentan relaciones violentas, ya no de su situación, sino de impedir la lucha contra la violencia de género.

\section{IMPOSIBLES DE PARAR: AGRESORES COMO HIPER-SUJETOS}

La construcción mediática del hombre-agresor se encuentra en las antípodas de la mujer-víctima objetualizada o relegada a cuasi-sujeto. Este encarna la idea de sujeto moderno y la violencia de género será interpretada, según el discurso hegemónico, como una conducta racional, pensada y calculada para retener el poder y dominar a las mujeres, interpretación heredera del 
feminismo radical de los 80. Los esfuerzos analíticos para distinguir dominación y violencia (García Selgas, Casado; Rodríguez Martínez; Wieviorka) nos llevan a distanciarnos, sin embargo, de esta definición: mientras que la dominación -situación de desigualdad y opresión que puede o no ser violentas- exigiría legitimación por parte tanto de quien domina como de quien es dominado que «se adhieren al orden social porque no dispone de otro instrumento de conocimiento que aquel que comparte con el dominador» (Bourdieu 51); la violencia aparecería cuando su uso queda desprovisto de legitimidad, cuando sobrepasa lo que se considera socialmente aceptable en un contexto determinado. Atendiendo a esta diferenciación, muchos postulan que la violencia aparece justo cuando el poder deja de estar legitimado. Para Castells y Subirats (138-145), la violencia será un síntoma del agrietamiento del patriarcado. Desde una perspectiva menos optimista, Kimmel lo teoriza como la percepción masculina de «derecho frustrado»: la violencia significaría tomar el poder que se cree con derecho de poseer (Kimmel 101-102). La violencia sería reactiva (Wieviorka) y su uso sería compensatorio para poder restablecer, aunque sea por un instante, la sensación de tener el poder.

El uso de la violencia, por tanto, sería expresivo y estaría relacionado con las dificultades de llegar a encarnar el modelo de masculinidad hegemónica (Connell; Connell, Messerschmidt) en un contexto de desigualdad creciente, donde las barreras económicas, sociales y políticas dificultan la tarea de devenir sujeto.

Así, a la visión de la violencia como una estrategia racional de los hombres para mantener y reproducir el orden patriarcal se contrapone la que verá en la violencia de género el receptáculo de los desequilibrios, zozobras y desasosiegos contemporáneos (Casado 12) que imprimen, no sólo las transformaciones en las relaciones de género sino también la profundización en las desigualdades en los órdenes económicos y de acceso a los modelos hegemónicos de masculinidad y feminidad. Esta tesis ha sido expuesta en investigaciones que han estudiado a hombres implicados en relaciones violentas quienes pocas veces postulan la vuelta al poder del padre ni apuestan por una estricta división del trabajo (Anderson, Umberson; Garcia Selgas, Casado). Según Kaufman, «las entrevistas con violadores y con hombres que han golpeado a mujeres muestran no sólo desprecio hacia ellas, sino frecuentemente un odio y un desprecio mucho más profundos hacia sí mismos. Es como si, incapaces de soportarse, atacaran a otros posiblemente para infligir sentimientos similares a quienes han sido definidos como un blanco socialmente aceptable, para experimentar una sensación momentánea de poder y control» (Kaufman 9). Porque, en palabras de María Jesús Izquierdo, «quien tiene el poder y además 
se encuentra en una posición dominante consigue el sometimiento sin necesidad de agredir» (Izquierdo 228). Con esto no se pretende negar la existencia de discursos sociales profundamente machistas sino que tratamos de poner de manifiesto cómo los modos de visibilización de la violencia de género en el contexto español han producido una sustantivación del maltratador que se asimila con un modelo de varón machista, celoso de las transformaciones en las relaciones de género con lo que, al mismo tiempo, la violencia se convierte en un residuo del pasado en la senda de la democratización (Casado).

En el discurso, la figura del hombre-agresor queda asociada a la del estratega omnipotente hacia el cual también falla la función interpretativa. En este caso, se le intenta disuadir mostrando las consecuencias que el uso de la violencia tiene para los agresores. Este intento de modular su conducta, sin embargo, se considera inocua para un hiper-sujeto que incluso se desiste y se traslada la interpelación a otros sujetos:

No, yo creo, hombre, para el agresor ése, no; para otros agresores, sí. Yo creo que el... lo que es muy positivo, y nosotros casi siempre lo intentamos enseñar, es el enseñar al agresor y decir «Éste es el tío y que además lo que hizo le va a salir carísimo, le va a salir por treinta años, veinte años», y yo creo que eso sí que es bueno que se sepa... (E6)

De acuerdo con esta perspectiva, mostrar la severidad de la punición se percibe como la mejor estrategia para contribuir a la lucha contra la violencia. Se trataría de volver al castigo cuando la disciplina falla. Para ello, se solicita la colaboración de la judicatura para permitir el acceso físico a los sujetos de la violencia para mostrar a los agresores:

Una de las cosas que echamos de menos, es que... a mí me gustaría...esto es una guerra personal mía... a mí me gustaría que... ehm... tuviésemos herramientas para criminalizar al agresor... [...] ...es decir, a los agresores nunca los vemos. Los vemos sentados en el banquillo, alguna vez... en un juicio... entonces a mí me gustaría que nosotros pudiésemos acceder a esa, a esa... por supuesto la presunción de inocencia va por... no vamos a sacarle la cara del señor si ese señor está condenado, pero si está en juicio, pues sacarle a lo mejor a él entrando en el juicio... igual que se hacen con millones de cosas [...] Pues yo echo en falta ese tipo de imágenes. Entonces bueno, pues si las tuviésemos nos ayudaría un montón a contar el problema de la violencia de género. (E11)

La argumentación que subyace es la capacidad explicativa que condensaría la figura del agresor que, al situarlo como sujeto de la acción violenta, permitiría identificar que detrás de los actos opera la violencia masculina. Ahora bien, mostrando se construye una identidad mediática del sujeto agresor que, como en el caso de la identidad de la mujer víctima, se muestra compacta al 
perfilar «al maltratador». No obstante, esta identificación reificada se entenderá como un servicio que el periodismo promueve para la detección y valoración del riesgo al desvelar cómo es «el maltratador», dotado de una identidad fija caracterizada por el uso habitual de la violencia en las relaciones con sus parejas. La constatación de la existencia de denuncias previas, por ejemplo, constituirá una de esas evidencias que se entienden como objetivas e inequívocas para la sociedad en conjunto y para la posible víctima.

La promoción de una identidad mediática del sujeto-agresor, siguiendo a Foucault, permitirá aislar unas prácticas para provocar la sensación de «dominar el acontecimiento aleatorio y esquivar su pesada y temible materialidad» (Foucault 1992, 5). El riesgo se minimiza al reducir el grupo de sujetos que se saben violentos -los que tienen denuncias previas, los que matan, los que agreden físicamente...- a través de la acción del sistema policial y judicial. Pero, al mismo tiempo, el peligro se difumina en el cuerpo social cuando los medios reiteran que el agresor «era un tipo normal»: cualquiera puede ser un maltratador. Los violentos aparecen cerca y, a la vez, lejos, tal y como explicaba Foucault, haciendo más aceptable y deseable el conjunto de controles judiciales y policiales. Se identifica la violencia como lejana por lo que respecta a su naturaleza, pero próxima por lo que respecta a la cotidianeidad, convirtiéndola en una amenaza constante para el orden moral (Foucault 1976).

Una última imagen del discurso de los y las periodistas es la del maltratador que no tiene miedo a las consecuencias de su acción:

Pues en violencia de género pasa algo parecido, habitualmente el homicida de violencia de género no intenta huir luego, muchas veces se entrega, llama él mismo, se sabe quién ha sido, está en su casa, no intenta huir [...] no intentan escapar, no intentan escapar ni, ni, ni hacer como que la ha matado una tercera persona, ¿no? Entonces, por eso, una orden de alejamiento no tiene por qué servir, a mí me pueden prohibir acercarme a ti, pero si no me importa lo que vaya a pasar, yo me acerco y te mato. Entonces, muchas veces también las instituciones sí ponen de su parte lo que se pueda, pero es que ante un tipo que le da igual lo que le pase... (E9)

Esta imagen aporta dos elementos más a la identificación mediática del sujeto agresor y al reconocimiento de la violencia de género. En primer lugar, la violencia se torna inevitable, autónoma e imparable por la acción del Estado. En segundo lugar, ontologiza la identidad y niega las posibilidades de dejar de ser un maltratador, con lo que se niega la renegociación constante de las identidades y las transiciones:

O sea, que yo, los mensajes que doy, las noticias que doy, no es para los maltratadores, porque con ellos no voy a poder hacer nada. Un maltratador es 
un maltratador y o decide buscar ayuda, o siente el rechazo de la sociedad y eso hace que se frene, o no hacemos nada. O sea, yo con mi noticia no voy a cambiar al maltratador. Voy a intentar cambiar o incidir en la maltratada. Voy a intentar ayudarla a ella, voy a intentar que denuncie, voy a intentar hacerle sentir que no está sola, que esto le pasa a más, que no puede permitirlo... (E2)

La cita explicita el cierre de círculo argumental: aunque la responsabilidad de cometer la agresión es del agresor, es la víctima la que tiene la responsabilidad de buscar la salida a la violencia a través de la denuncia.

\section{CONCLUSIONES}

A pesar de la variabilidad de la muestra, encontramos un discurso muy compacto en cuanto al reconocimiento de los sujetos de la violencia y el papel que juegan los medios para interpelarlos. Independientemente de la naturaleza de la cadena, la especialización y la capacidad de decisión, las representaciones de los sujetos de la violencia se encuentran mediados por un discurso hegemónico sobre la violencia de género y el papel de los medios que limita notablemente la capacidad de renovación del marco representacional.

En primer lugar, la violencia se interpreta preeminentemente desde el orden moral, no desde la dimensión estructural y la crítica a las desigualdades, hecho que se plasma en una cobertura centrada en los sujetos de la violencia. En segundo lugar, la falta de referencias a los ejes de desigualdad en los que se funda la violencia invisibiliza las diversas posiciones sociales consecuencia de la intersección de los múltiples ejes de opresión que se articulan con el orden de género. Esto se traduce en la unificación del sujeto mediático de la violencia, dificultando el reconocimiento de todo contexto de la violencia que se aleje de la identidad mediada.

El proceso de introducción de la violencia en la esfera pública se ha saldado con la simplificación de la violencia de género como realidad social y constructo conceptual. Esta simplificación, si bien habría servido para poner en el foco una realidad anteriormente silenciada, ahora (re)produce las identidades de género bajo la dicotomía sujeto-objeto y las ontologiza en sus argumentaciones. Las identidades mediáticas del sujeto-víctima y del sujeto-agresor se consideran estables bajo la interpretación de la violencia como racional. Hemos discutido cómo la complejidad de la dinámica de la violencia de género supera las definiciones hegemónicas en las que, además, se le atribuye su uso a una única realización del género.

Este ejercicio de producción de unas identidades reificadas, fetichizadas y aptas para el consumo mediático (Gámez Fuentes, Núñez Puente 148) se 
fundan en el juicio de valor. El juicio de valor, tal y como argumenta Butler, no funda una relación ética ni presupone el reconocimiento (Butler 67). Es más, el juicio actúa como una vía rápida «de postular una diferencia ontológica entre juzgador y juzgado, y aun de depurarse del otro [...] la condena suele ser un acto que no sólo 'abandona' al condenado, sino que procura infligirle una violencia en nombre de la 'ética'» (Butler 68). Este ejercicio de violencia se materializa en los medios con la exclusión de los sujetos de la violencia del discurso mediático de los que se desconfía cuando no reproducen el discurso hegemónico.

Por último, hemos mostrado cómo se alteriza a los sujetos de la violencia. En el discurso de los y las periodistas, los violentos son siempre los otros, también las violentadas son las otras. Otros en los que no nos reconocemos, y por eso se les interpela de manera asimétrica, al mismo tiempo que se delimitan unos contornos de la violencia con lo que se pretende aislar y objetivar el problema social mediado por el juicio moral.

Transformar este esquema de reconocimiento limitado y parcial de la violencia de género significaría apostar por otro tipo de interpelación que permitiese explorar los caminos de las resistencias y (re)conocer las realidades que se esconden debajo de las identidades mediáticas. Una interpelación dialógica que permita enriquecer el debate público sobre la violencia de género más allá de una comprensión que individualiza los problemas sociales e institucionaliza las respuestas.

\section{REFERENCIAS BIBLIOGRÁFICAS}

Anderson, Kristin L. y Debra Umberson. «Gendering violence. Masculinity and Power in Men's Accounts of Domestic Violence». Gender and Society 15.3 (2011): 358-380.

Bengoechea, Mercedes. «En el umbral de un nuevo discurso periodístico sobre violencia y agencia femenina: de la crónica de sucesos a la reseña literaria». CIC. Cuadernos de Información y Comunicación 5(2000): 9-22.

Berganza Conde, María Rosa. «La construcción mediática de la violencia contra las mujeres desde la Teoría del Enfoque». Comunicación y Sociedad 16.2 (2003): 9-32.

Bolinches, Emília. Notícies amb llaç blanc. Manual per a periodistes sobre la violència domèstica. València: Unió de Periodistes Valencians-Generalitat Valenciana, 2002.

Bourdieu, Pierre. La dominación masculina. Barcelona: Anagrama, 2000.

Butler, Judith. Dar cuenta de sí mismo. Violencia ética y responsabilidad. Buenos Aires: Amorrortu, 2009. 
Callejo, Javier. «Medios, género y poder». Profesionales del periodismo. Hombres y mujeres en los medios de comunicación. Coords. Marisa García de Cortázar y M. ${ }^{a}$ Antonia García de León. Madrid: CIS, 2000, 1-30.

Carballido, Paula. El proceso de construcción de la violencia contra las mujeres: medios de comunicación y movimiento feminista. Una aproximación desde la teoría del framing. (Tesis Doctoral). Castellón: Universitat Jaume I, 2010.

Casado Aparicio, Elena. «Tramas de la violencia de género: sustantivación, metonimias, sinécdoques y preposiciones». Papeles del CEIC 85(2012): 1-20.

Castells, Manuel y Marina Subirats. Mujeres y hombres: ¿un amor imposible? Madrid: Alianza Editorial, 2007.

Conde, Fernando. Análisis sociológico del sistema de discursos. Madrid: CIS, 2009.

Connell, R.W. y James W. Messerschmidt. «Hegemonic masculinity: rethinking the concept». Gender and Society 19 (2005): 829-859.

Connell, Raewyn. Gender. Short Introduction. Cambridge: Polity Press, 2009.

Cuklanz, Lisa M. «Mass media representation of gender violence». The Routledge Companion to Media \& Gender. Eds. Cynthia Carter, Linda Steiner y Lisa McLaughlin. London: Routledge, 2014, 32-41.

De Lauretis, Teresa. «The violence of rhetoric: Considerations on representation and gender». Semiotica 54.1/2 (1985): 11-31.

De Lauretis, Teresa. Technologies of Gender. Essays on Theory, Film, and Fiction. Bloomington: Indiana University Press, 1987.

De Miguel, Ana. «El movimiento feminista y la construcción de marcos de interpretación. El caso de la violencia contra las mujeres». RIS 35 (2003): 127-150.

Fagoaga, Concepción. La violencia en los medios de comunicación. Maltrato a la pareja y agresión sexuada. Madrid: Dirección General de la Mujer, 1999.

Fairbairn, Jordan y Myrna Dawson. «Canadian News Coverage of Intimate Partner Homicide: Analyzing Changes Over Time». Feminist Criminology 8.3 (2013): 147-176.

Farré Coma, Jordi y Juan Luis Gonzalo Iglesia. «La comunicació de risc. Més enllà dels mitjans: i els periodistes?». Periodística 14 (2012): 9-23.

Fernández Díaz, Natalia. La violencia sexual y su representación en la prensa. Barcelona: Anthropos, 2003.

Foucault, Michel. Vigilar y castigar. México: Siglo XXI, 1976.

Foucault, Michel. El orden del discurso. Buenos Aires: Tusquets, 1992.

Gámez Fuentes, María José. «Sobre los modos de visibilización mediático-política de la violencia de género en España: consideraciones críticas para su reformulación». OBETS. Revista de Ciencias Sociales 7.2 (2012): 185-213.

Gámez Fuentes, María José. «Re-Framing the Subject(s) of gender Violence». Peace review: A Journal of Social Justice 25 (2013): 398-405.

Gámez Fuentes, María José y Sonia Núñez Puente. «Medios, ética y violencia de género: más allá de la victimización». Asparkia 24 (2013): 145-160. 
García Selgas, Fernando y Elena Casado. Violencia en la pareja: género y vínculo. Madrid: Talasa, 2010.

Gilchrist, Kristen. «Newsworthy victims? Exploring diferences in Canadian local press coverage of missing/murdered Aboriginal and White women». Feminist Media Studies 10.4 (2010): 373-390.

Gómez Nicolau, Emma. La violència de génere en el discurs televisiu. Procés de producció i representació mediática (Tesis Doctoral). Valencia: Universitat de València, 2015.

Hall, Stuart. «Codificación y descodificación en el discurso televisivo». Cuadernos de Información y Comunicación 9 (2004): 210-236.

Howe, Adrian. Sex, Violence and Crime. Foucault and the 'Man' Question. Abingdon, Oxon: Routledge-Cavendish, 2008.

IORTV. Manual de urgencia. Mujer, Violencia y Medios de Comunicación. Madrid: IORTV (RTVE), 2002.

Izquierdo, María Jesús. «Estructura y acción en la violencia de género». Violencia deliberada. Las raíces de la violencia patriarcal. Ed. Maria Dolors Molas Fons. Barcelona: Icaria, 2007, 223-234.

Jiwani, Yasmin. Discourses of Denial: Mediations of Race, Gender, and Violence. Vancouver: UBC Press, 2006.

Jiwani, Yasmin y Mary Lynn Young. «Missing and Murdered Women: Reproducing Marginality in News Discourse», Canadian Journal of Comunication 31 (2006): 895-917.

Kaufman, Michael. «Men, Feminism, and Men's Contradictory experiences of Power». Theorizing Masculinities. Eds. Harry Brod y Michael Kaufman. Thousand Oaks: Sage Publications, 1994, 59-83.

Kimmel, Michael. «Contextualizing Men's Violence. The Personal Meets the Political». Gender Violence: Interdisciplinary Perspectives. Eds. Jessica Schiffman y Margie Edwards. New York: New York University Press, 2007, 99-110.

Larrauri, Elena. «¿Por qué retiran las mujeres maltratadas las denuncias?». Revista de Derecho Penal y Criminología 12(2003): 271-307.

López Díez, Pilar (dir.) Representación de la violencia de género en los informativos de TVE. Madrid: IORTV (RTVE), 2006.

Lledó, Eulàlia. Cómo tratar bien a los malos tratos. Manual de Estilo para los Medios de Comunicación. Sevilla: Instituto Andaluz de la Mujer-RTVA, 1999.

Luna del Castillo, Juan. Informe preliminar sobre la distribución espacio-temporal de los femicidios habidos en España entre los años 2003 al 2010. Madrid: Ministerio de Sanidad, Política Social e Igualdad. Delegación del Gobierno para la violencia de género, 2011.

Maqueda Abreu, Maria Luisa. «¿Es la estrategia penal una solución a la violencia contra las mujeres?» InDret 4 (2007): 1-43. 
Marugán, Begoña y Cristina Vega. «El cuerpo contra-puesto. Discursos feministas sobre la violencia contra las mujeres». VIII Congreso de Sociología, Salamanca, 2001 <http://www.sindominio.net/Karakola/textos.htm> consultado el 19-06-2013.

Marugán, Begoña y Cristina Vega. «Gobernar la violencia: apuntes para un análisis de la rearticulación del patriarcado». Política y Sociedad 39.2 (2002): 415-435.

Meyers, Marian. News Coverage of Violence against Women. Engendering blame. Thousand Oaks: Sage Publications, 1997.

Miranda López, M. ${ }^{a}$ Jesús. «La retórica de la violencia de género. Etnometodologia de un tipo delictivo». Amor, razón, violencia. Eds. M. ${ }^{a}$ Jesús Miranda López, M. ${ }^{a}$ Teresa Martín Palomo y Begoña Marugán Pintos. Madrid: Editorial Catarata, 2009, 1-40.

Moorti, Sujata. Color of Rape. Gender and Race in television's Public Spheres. Albany: State University of New York Press (SUNY Press), 2002.

Núñez Puente, Sonia y Diana Fernández Romero. «Construcción identitaria del sujeto víctima de violencia de género: fetichismo, estetización e identidad pública». Revista Teknokultura 12.2 (2015): 267-284.

Osborne, Raquel. «Construcción de la víctima, destrucción del sujeto». Página Abierta 206 (2009): 8-13.

Paterson, Stefanie L. «Rethinking Wife Abuse: Violence, Resistance, and Public Policy in Canada». Canadian Political Science Association, 2006. <http://www. cpsa-acsp.ca/papers-2006/Paterson.pdf> consultado el 12-04-2013.

Rodríguez Magda, Rosa María. «El Feminismo Sitiado. Corrientes y debates en la España actual». Revista Observaciones Filosóficas 12 (2011). <http:// www.observacionesfilosoficas.net/elfeminismositiado.htm> consultado el 20-12-2015.

Rodríguez Martínez, Pilar. «Feminism and Violence: The Hegemonic Second Wave's Encounter with Rape and Domestic Abuse in USA (1970-1985)». Cultural Dynamics 23.3 (2011): 147-172.

Sokoloff, Natalie J. e Ida Dupont. «Domestic Violence at the Intersection of Race, Class and Gender. Challenges and Contributions to Understanding Violence Against Marginalized Women in Diverse Communities». Violence against Women, 11.1 (2005): 38-64.

Verdugo Martí, Vicenta. «Desmontando el patriarcado: prácticas políticas y lemas del movimiento feminista en la transición democrática». Feminismo/s 16(2010): 259-279.

Vives Cases, Carmen. La violencia contra la mujer en el espacio discursivo público. Madrid: Centro Reina Sofía para el Estudio de la Violencia, 2005.

Wieviorka, Michel. «Ante la violencia». El doble filo de la navaja: violencia y representación. Eds. Fernando García Selgas y Carmen Romero Bachiller. Madrid: Editorial Trotta, 2006, 29-44. 